\title{
Effects of heating rates and SBE loading on sintered properties of spent bleach earth/recycled glass composite
}

\author{
N. Salleh, Z. Shamsudin*, J. M. Juoi and Z. Mustafa \\ Advanced Manufacturing Centre, Faculty of Manufacturing Engineering, \\ Universiti Teknikal Malaysia Melaka, 76100 Durian Tunggal, Malacca, Malaysia \\ *Email: zurina.shamsudin@ utem.edu.my \\ Phone: +6063316441; Fax: +6063316431
}

\begin{abstract}
The purpose of this study is to investigate the influence of different heating rates on the properties of glass ceramic composite (GCC) at different spent bleach earth (SBE) loadings. GCC was prepared using SBE and recycled soda lime silicate (SLS) glass. The particle size of SLS glass was approximately $<45 \mu \mathrm{m}$. The GCC was formed by uniaxial dry pressing at weight fractions of SBE loading of $40 \mathrm{wt} . \%, 45 \mathrm{wt} . \%$, and $55 \mathrm{wt}$. \%. The GCC was then sintered at different heating rates of $2{ }^{\circ} \mathrm{C} / \mathrm{min}, 4{ }^{\circ} \mathrm{C} / \mathrm{min}, 6{ }^{\circ} \mathrm{C} / \mathrm{min}$ and 8 ${ }^{\circ} \mathrm{C} / \mathrm{min}$ at $700{ }^{\circ} \mathrm{C}$ of sintering temperature. The GCC specimens were analysed in terms of their physical properties, while crystalline phase and microstructure were characterised using X-Ray diffraction and scanning electron microscope (SEM), respectively. The results from X-Ray diffraction pattern showed that quartz and wollastonite phases were formed with no major changes on the phases as the heating rate increased. The results indicate that the variation of heating with $2{ }^{\circ} \mathrm{C} / \mathrm{min}$ interval does not give a remarkable result of physical properties on GCC. High loading of SBE sintered at $2^{\circ} \mathrm{C} / \mathrm{min}$ of heating rate produced low water absorption, density and porosity. SEM analysis showed that the physical properties and crystalline phases were correlated to the SBE loading and changes in the heating rate. The study concluded with the prospect of continuing the work of optimisation on schedule heat treatment at sintering temperature regimes.
\end{abstract}

Keywords: Heating rate; spent bleach earth; glass ceramic composite.

\section{INTRODUCTION}

An immediate attention towards waste management is required in all countries including Malaysia [1]. The urgency is needed as health and environmental implications are always associated with solid waste management [2]. Due to that, the recycling of soda lime silicate glass (SLS) is preferable as it is very safe and not an expensive method [3]. Besides, it is the inspiration of researches to integrate other natural waste materials into the recycled SLS glass [4-6]. Spent bleach earth (SBE) is a natural waste from palm oil refineries and high volumes of it being disposed through landfill is problematic due to the oil on the surface area of the SBE particles which are exposed to oxygen from the environment, thus producing rapid oxidation and adequate heat to ignite the oil. This disposal method has been banned by the European Union (EU) landfill directive [7]. This disposal method is also very costly and needs to be paid by refineries [8]. Hence, a recycling method is extensively needed to control the consequences mentioned. The 
potential use of SBE as a clay substitute in the production of brick and tile manufacturing had been highlighted by many researchers $[9,10]$. The recent research on the formation of pore forming brick by Quesada and Iglesias [10] reported that the optimum composition was $10 \mathrm{wt}$. \% of SBE which resulted in good properties of clay brick formulation. The outstanding properties and densification of GCC can be achieved by controlling the sintering aspects during heat treatment [11, 12]. Consequently, the fundamental parameters (heating rate, composition, sintering temperatures, etc.) that control the performance of glass ceramic are often related to the development of its microstructure. Controlled heating rate that dictates the final properties of glass ceramic composite reflects these factors. Research on heating rate showed that fast heating rate contributed to the highest shrinkage and lowest porosity [1] and it was also affected by the composition of the materials [5]. At high content of glass, a slow heating rate promoted the formation of nuclei [13], while a fast heating rate produced a formation of substantial crystallisation [5]. At low content of glass, no large difference on porosity was observed and the crystallisation appeared to be progressive [5]. Although the investigation of general properties of glass composite based recycle glass has been explored in various research, research on SBE for reinforced composite is still in its early stage. Hence, this work is aimed to study the effects of heating rate on the physical properties and microstructure of GCC at high SBE loading with the expectation of improving the properties of GCC.

\section{METHODS AND MATERIALS}

The flow process of the preparation of glass ceramic composite is shown in Figure 1. The raw SBE has undergone a cleaning process to extract oil using the sonification process. It was then followed by filtration and drying processes under sunlight until no wet SBE powder was observed. The particle size distribution for SBE was determined using a particle size analyser, the Mastersizer 2000 (Malvern, UK Instrument Ltd.) model. SLS recycled glasses were sieved using a vibratory sieve shaker to get $<45 \mu \mathrm{m}$ average particle size. The transition temperatures $\left(T_{g}\right)$ of SBE and recycled SLS glass were investigated using a differential thermal analysis (DTA) model Hitachi STA 7300 (Hitachi, Japan). The compositions of the GGC composite investigated in this work are shown in Table 1. All samples were produced using conventional powder processing methods involving ball milling, pressing and sintering. $3.2 \mathrm{~g}$ of mixture were pressed into a square mold $(18 \mathrm{~mm}$ $\mathrm{x} 18 \mathrm{~mm} \times 4 \mathrm{~mm})$ at $30 \mathrm{MPa}$. The obtained green bodies were subjected to sintering treatments using a laboratory electric furnace Carbolite 1300 (Carbolite, German) at different heating rates of $2^{\circ} \mathrm{C}, 4^{\circ} \mathrm{C}, 6^{\circ} \mathrm{C}$ and $8^{\circ} \mathrm{C}$ with a constant sintering temperature of $700{ }^{\circ} \mathrm{C}$ and 1 hour of dwelling time. In order to have a fundamental sintering profile of sintered glass ceramic made up of SBE, the minimum interval of $2^{\circ} \mathrm{C} / \mathrm{min}$ of heating rate was chosen to sinter the samples. The physical analyses of water absorption, bulk density and apparent porosity were determined according to the modified ASTM C373. The crystalline phase analysis was conducted using X-ray diffraction (RIGAKU Model MINIFLEX II) operating at $30 \mathrm{kV}$ and $15 \mathrm{~mA}$ with $\mathrm{Cu} \mathrm{K} \alpha$ radiation. The detector was scanned in the range of $2 \theta$ angle from $10^{\circ}$ to $80^{\circ}$. The appeared crystalline phases were compared with ICDD and X'Pert Highscore software to analyse the data. Scanning electron microscopy (SEM) (EVO 50 Carl Zeiss SMT, UK). The surface of the samples was polished using $3 \mu \mathrm{m}$ and $1 \mu \mathrm{m}$ diamond paste to obtain mirror surface finishing. The samples were then cleaned in acetone for 2 mins. Later, the samples were Au-coated to ensure that they were conductive. 


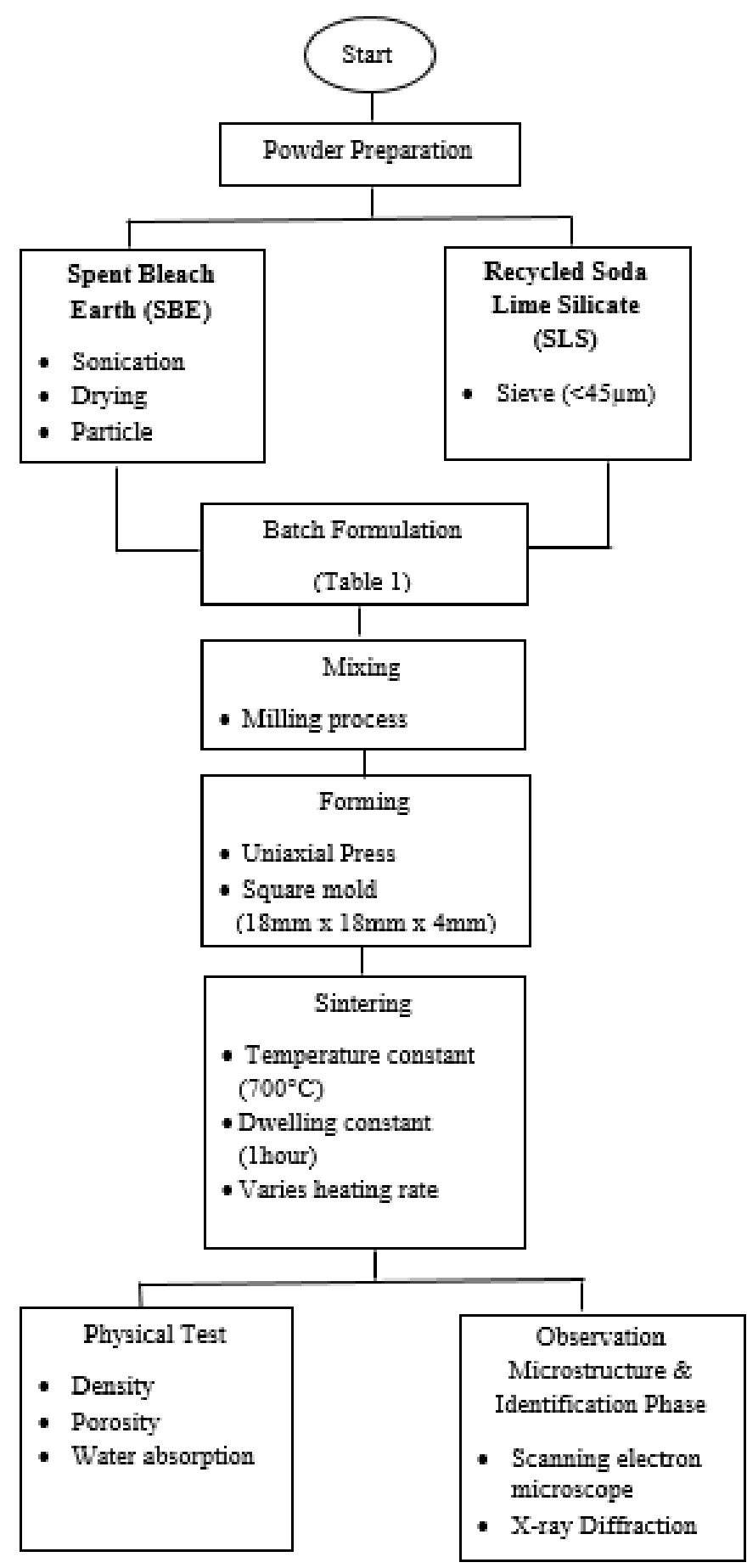

Figure 1. Flow process for spent bleach earth (SBE)/soda lime silicate (SLS) composite.

Table 1. Composition of SBE to recycled SLS glass (wt. \%).

\begin{tabular}{|c|c|c|}
\hline SBE & (wt. \%) & Recycled SLS glass (wt. \%) \\
\hline & 40 & 60 \\
\hline & 45 & 55 \\
\hline & 55 & 45 \\
\hline
\end{tabular}




\section{RESULTS AND DISCUSSION}

\section{Differential Thermal Analysis - (DTA) \\ Recycled soda lime silicate (SLS) glass}

The differential thermal analysis - thermogravimetric (DTA-TG) curve for recycled SLS glass is presented in Figure 2. A series of endothermic and exothermic reactions were observed on a temperature range of 60 to $1000{ }^{\circ} \mathrm{C}$. Upon heating the glass powder to 1000 ${ }^{\circ} \mathrm{C}$ at $10^{\circ} \mathrm{C} / \mathrm{min}$, the sample exhibited one endothermic and exothermic peaks each which were represented as transition glass, $T_{g}$ and crystallisation temperature $T_{c}$. The value of the glass transition temperature was determined from the intersection of two targets at the start of the corresponding endothermic.

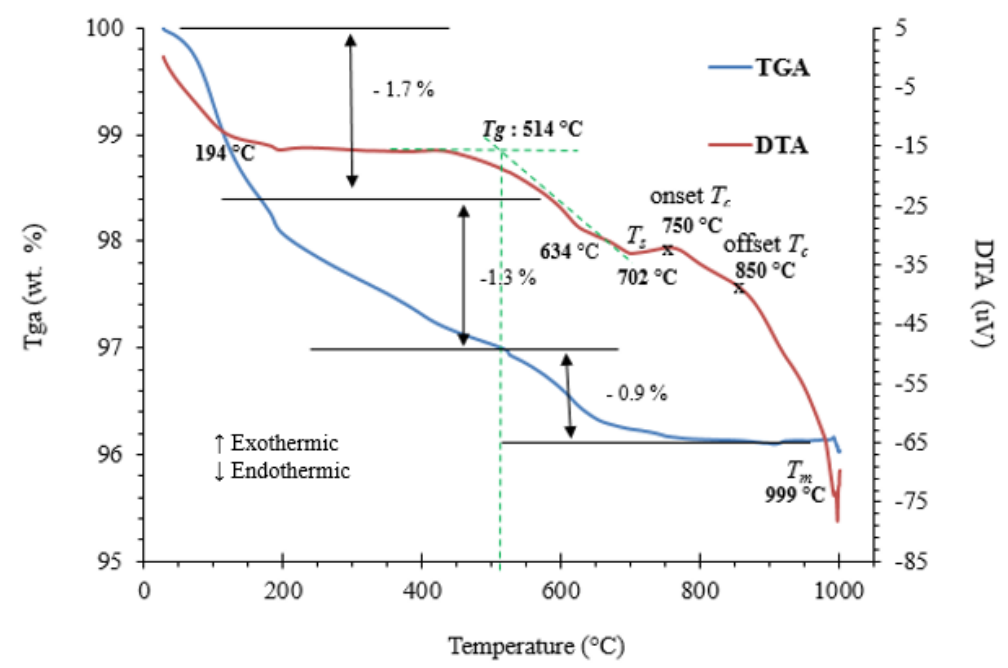

Figure 2. DTA-TG curve of recycled soda lime silicate (SLS) glass.

The glass transition temperature was determined to be approximately at $514^{\circ} \mathrm{C}$ as shown in Figure 2 after extrapolated from the start and end of the transition. An endothermic reaction appeared after $T_{g}$ which indicated sintering ability and promotion of sinter crystallisation process [4]. Investigation by [14] found that at the range between $T_{g}$ and $T_{c}$, the quartz inversion occurred on the sample of glass ceramic. Pontikes et al. also reported that a small endothermic with a broad shape appeared before the onset of $T_{c}$ and associated it with the entrapment of gasses due to the rearrangement of molecules in the glass structure. The crystallisation temperature, $T_{c}$ was in the range of $750{ }^{\circ} \mathrm{C}$ to 850 ${ }^{\circ} \mathrm{C}$ by the exothermic peak with a high shoulder. On $T_{c}$, the sample underwent intense crystallisation, thus, achieving a high degree of crystallisation and densification which is in agreement with [15]. The melting point, $T_{m}$ was at about $999^{\circ} \mathrm{C}$. The sources of glasses provided by Jabatan Galian Ipoh were initially mixed because the colour and the constituents of the glasses were not informed. They might came from window panes which contributed to the low melting point [5]. The presence of $\mathrm{Na}_{2} \mathrm{O}$ and $\mathrm{K}_{2} \mathrm{O}$ acted as glass modifier while $\mathrm{MgO}$ and $\mathrm{CaO}$ in the glass composition were able to reduce the glass viscosity [16]. Based on the DTA results, the samples were subjected to a single step crystallisation process or also called as direct sintering without considering the nucleation stage. It has been reported by Ponsot et al. [22] that works on recycled glass using direct sintering produced a good result in water absorption and specific strength. Since the present study is aimed to develop a heat treatment schedule, different ranges of heating rates were imposed in order to examine the effects on material properties, since the 
properties of glass ceramic were influenced by heating rate and temperature $[17,18]$. A summary of the main thermal event of recycled SLS glass is tabulated in Table 2.

Table 2. Summary of thermal event on recycled SLS glass

\begin{tabular}{lc}
\hline \multicolumn{1}{c}{ Thermal event } & Temperature $\left({ }^{\circ} \mathrm{C}\right)$ \\
\hline Transition temperature $\left(T_{g}\right)$ & 514 \\
Softening temperature $\left(T_{s}\right)$ & 702 \\
Crystallisation temperature $\left(T_{c}\right)$ & $750-850$ \\
Melting temperature $\left(T_{m}\right)$ & 999 \\
\hline
\end{tabular}

\section{Spent Bleach Earth}

The differential thermal analysis - thermogravimetric (DTA-TG) curve for spent bleach earth (SBE) is presented in Figure 3. A series of endothermic and exothermic reactions were observed in the temperature range of 60 to $1200^{\circ} \mathrm{C}$. Weight loss of sample between $50-200{ }^{\circ} \mathrm{C}$ and endothermic peak centred at $100{ }^{\circ} \mathrm{C}$ may be due to the adsorbed water removal which was also reported by [19]. Weight loss of sample between $200-300{ }^{\circ} \mathrm{C}$ and exothermic peak centred at $225^{\circ} \mathrm{C}$ may be mostly due to the evaporation processes, which can be described as the evaporation associated with the evolution of oil from SBE [10]. Weight loss between $300{ }^{\circ} \mathrm{C}$ to $500{ }^{\circ} \mathrm{C}$ with exothermic peak centred at $312^{\circ} \mathrm{C}$ could be attributed to the decomposition and burning of organic content as reported by [20]. Waste was completely combusted at endothermic peak centred at $840{ }^{\circ} \mathrm{C}$ with $-6.85 \%$ of weight loss. A summary of the main thermal event of recycled SLS glass is tabulated in Table 3.

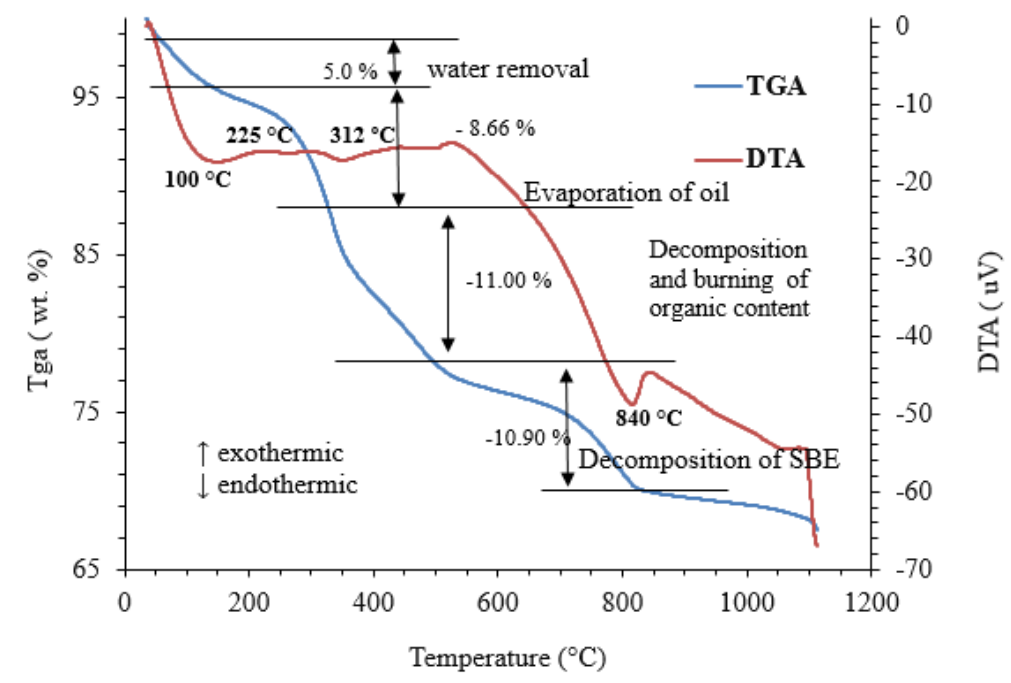

Figure 3. DTA-TG curve of spent bleach earth.

Table 3. Summary of thermal event on spent bleach earth.

\begin{tabular}{|c|c|c|}
\hline Thermal event & & Temperature $\left({ }^{\circ} \mathrm{C}\right)$ \\
\hline Evaporation of moisture & & 100 \\
\hline Evaporation of oil & & 225 \\
\hline Decomposition and burning of organic content & in $\mathrm{SBE}$ & 312 \\
\hline Decomposition of clay mineral in SBE & & 840 \\
\hline
\end{tabular}




\section{Physical Properties}

Figures 4-6 depict the bulk densities, porosities and water absorptions at different heating rates and SBE loadings. It was observed that as the SBE loading increased, the density, porosity and water absorption were not consistent for all heating rates. Lower water absorption produced high density as reported in the study by [20]. The low density at high SBE loading could also be supported by the research from Quesada and Iglesias [8]. The SBE was reported to have high pore character. Therefore, the density of high SBE loading was low as compared to the composition with high recycled SLS glass content. The porosity and water absorption results were inversely proportional to density [21].

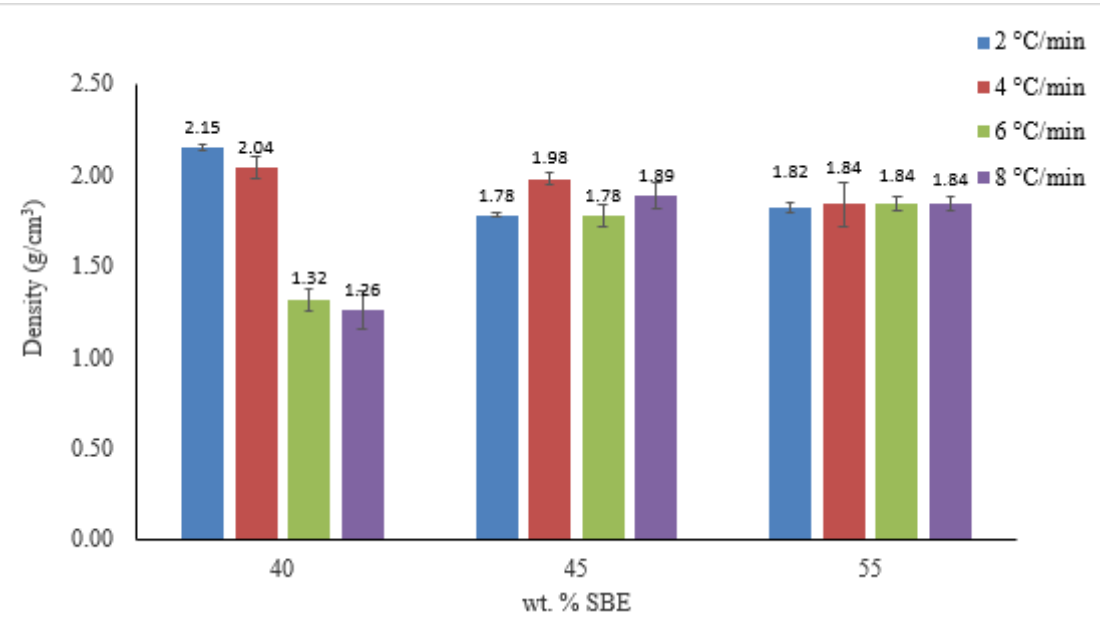

Figure 4. Percentage of bulk density of green GCC at different heating rates and SBE loadings.

When the heating rate increased by $40 \mathrm{wt}$. \% SBE, the density decreased, while the porosity and water absorption increased. The applied sintering temperature of $700{ }^{\circ} \mathrm{C}$ fell at the onset of crystallisation peak temperature of the recycled SLS glass. This optimum crystallisation peak temperature allowed the crystallisation to grow at a slow heating rate. Further increase in heating rate caused the "bloating" effect. This effect can cause microstructure failure. Therefore, the density would be extremely reduced and many pores would appear. These findings are in the same argument as those reported in the literature $[13,21]$. As the heating rate was decreased, high crystallisation took place at low crystallisation temperature. Thus, producing high density and low porosity and water absorption. Moreover, further increase in heating rate reduced the density caused by the "bloating" effect. In addition, porosity and water absorption would increase.

In this study, the density profile of $45 \mathrm{wt} . \%$ and $55 \mathrm{wt} . \%$ of SBE loading exhibited no major differences with average results between 1.78 to $1.98 \mathrm{~g} / \mathrm{cm}^{3}$ for all ranges of heating rates. These anomalous density results revealed the slight differences on porosity and water absorption values. Based on the DTA results, on 45 wt. \% SBE, a good densification with high crystallisation growth could be obtained at high heating rate when sintered at lower temperature than the crystallisation temperature of recycled SLS glass. The $700{ }^{\circ} \mathrm{C}$ of sintering temperature applied on the samples with a slow heating rate could not allow complete crystallisation to occur. Research finding by Sanad et al. [1] pointed out that when the sintering temperature applied was lower than the crystallisation peak temperature, fast heating rate allowed complete crystallisation to occur. Due to that, the densities should show lower values while porosity and water absorption should show 
higher values than reported. The increasing densities and decreasing water absorption and porosity on both samples were suspected to come from the inaccurate results of slightly dusty sample during the experiments. When the dusty sample was soaked into water, the weight of sample reduced and resulted in higher density values compared to the results of densities of sample at $6^{\circ} \mathrm{C} / \mathrm{min}$ and $8{ }^{\circ} \mathrm{C} / \mathrm{min}$. The same explanation can also be pointed out on the porosity and water absorption results.

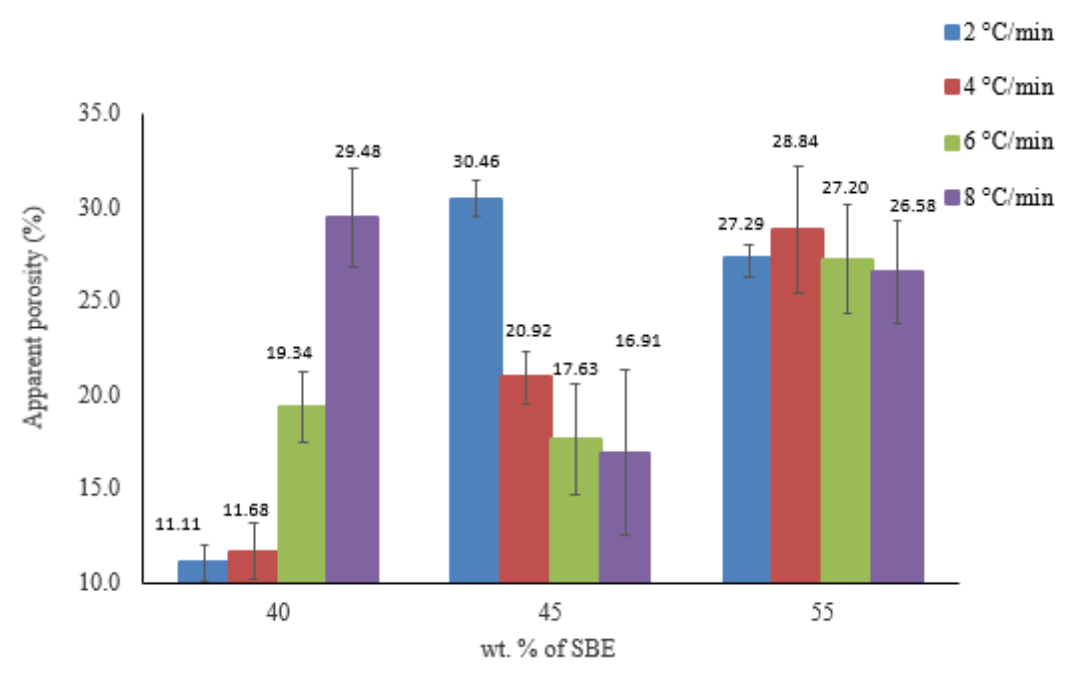

Figure 5. Percentage of porosity of green GCC at different heating rates and SBE loadings.

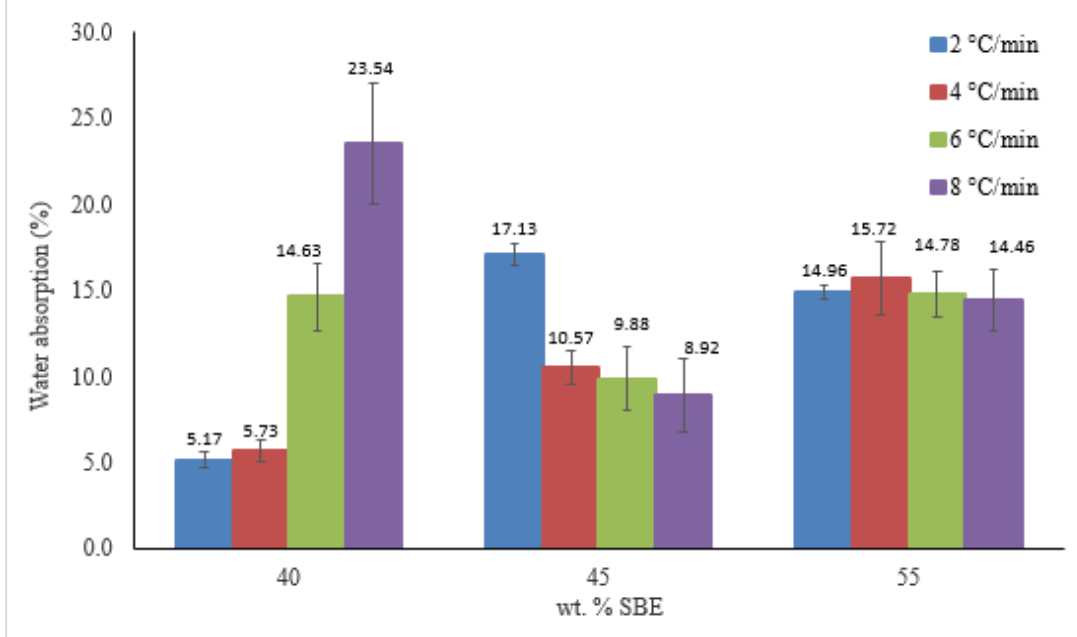

Figure 6. Percentage of water absorption of green GCC at different heating rates and SBE loadings.

A similar explanation was also given towards the anomalous result of density on 55 wt. $\%$ of SBE, in terms of the porosity and water absorption results. The addition of 55 wt. \% SBE increased the onset of crystallisation temperature. Due to that, the sample required higher interval of heating rate to obtain complete crystallisation with high densification. In addition, inconsistent density results were also affected by the reduction of weight on the samples at soaking condition during the density experiment. The highest density with low porosity and water absorption were recorded for the sample of $40 \mathrm{wt}$. \% SBE loading treated at $2^{\circ} \mathrm{C} / \mathrm{min}$ while the lowest density was exhibited by the sample of 
40 wt. \% SBE loading treated at $8{ }^{\circ} \mathrm{C} / \mathrm{min}$ with high values of porosity and water absorption. It may be deduced that the sample from 40 wt. \% of SBE had a good densification at slow heating rate. For $45 \mathrm{wt} . \%$ and $55 \mathrm{wt} . \%$ samples, they needed higher interval of heating rate in order to have high dispersion of nuclei and crystal growth with high densification of GCC.

\section{Microstructure and Phase Analysis}

Crystalline phase was identified based on the XRD pattern of the produced green GCC with 40 wt. \% SBE as shown in Figure 7. Different heating rates of $2{ }^{\circ} \mathrm{C} / \mathrm{min}, 4^{\circ} \mathrm{C} / \mathrm{min}$, $6^{\circ} \mathrm{C} / \mathrm{min}$, and $8^{\circ} \mathrm{C} / \mathrm{min}$ were discussed further with the phase presence. The dominant phases that appeared at all heating rates were quartz $\left(\mathrm{SiO}_{2}\right)$ and wollastonite $\left(\mathrm{CaSiO}_{3}\right)$. Weak diffraction peaks between $40^{\circ}$ and $70^{\circ}$ indicated a mainly glassy phase. As observed, the increase of heating rate did not contribute to the major formation of a new phase except for $8^{\circ} \mathrm{C} / \mathrm{min}$ where the beginning of very small peaks was observed. Even though this insignificant phase could not be identified by the software, the appearance indicated that the formation of new phases could be triggered at a higher rate than 8 ${ }^{\circ} \mathrm{C} / \mathrm{min}$. In addition, the intensities of phases appeared more intense at a high heating rate as compared to a low one. The high acceleration of temperature encouraged the particles to further interact with each other, thus producing stronger phases [1]. Owing to that, the slight effect on the phases resulted in low densities for all heating rates. Formation of quartz phase was expected since the major composition of SBE and recycled SLS glass is silica sand $\left(\mathrm{SiO}_{2}\right)$. The formation of wollastonite wa's due to the major availability of $\mathrm{CaO}$ in the recycled SLS glass [14]. The formation of quartz and wollastonite phases was also proven as both phases were easily formed at lower temperature [22, 23].

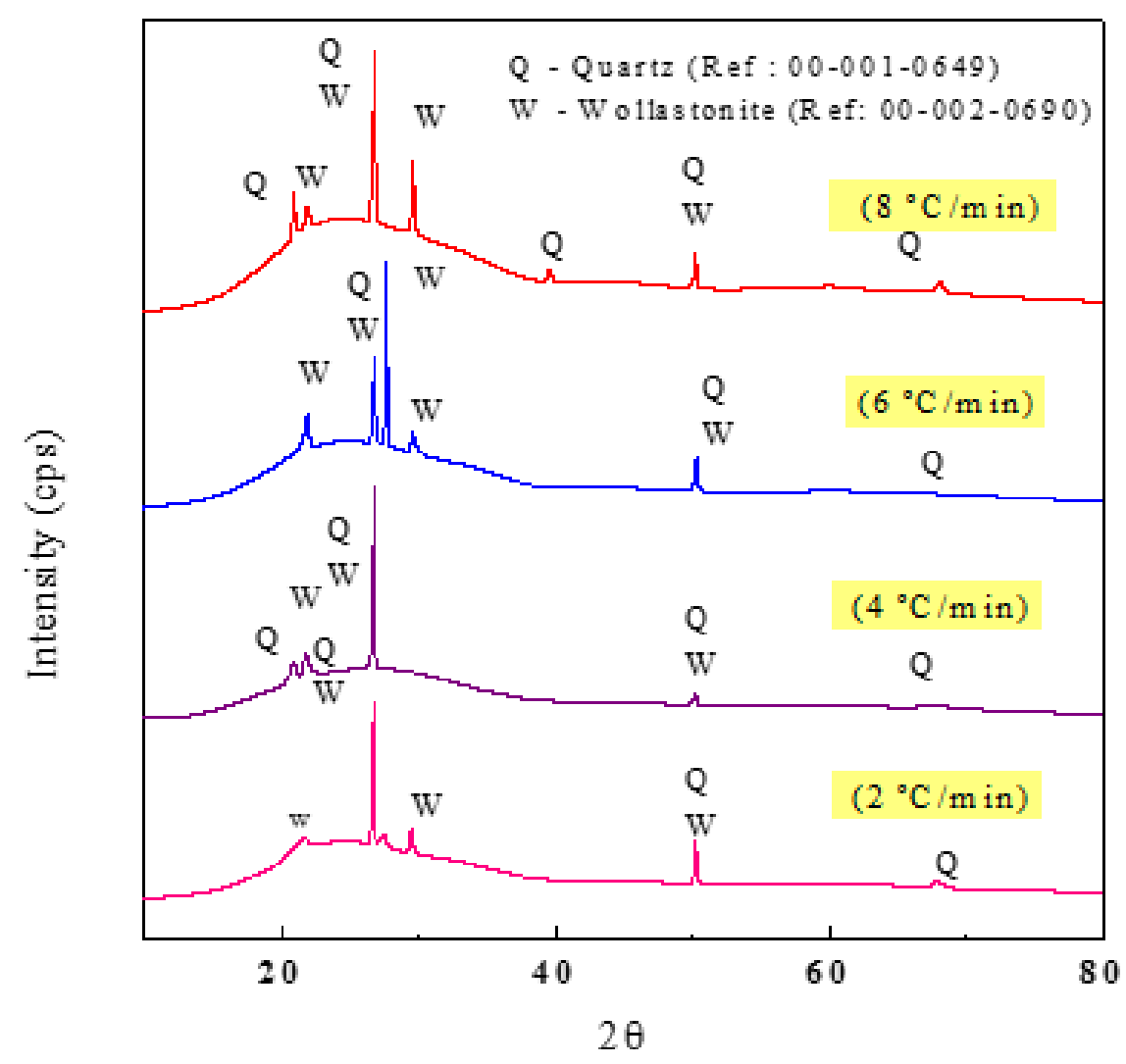

Figure 7. XRD pattern of green GCC on $40 \mathrm{wt} \%$ SBE at different heating rates. 
Figure 8 presents a scanning electron microscopy (SEM) micrograph of crosssectioned green GCC produced from different heating rates and SBE loadings. Less uniform and less densified microstructures were obtained at all heating rates when the SBE loading increased. Irregular shape and interconnected pores were also observed. This microstructure observation is in the same argument with the literature from Quesada and Iglesias [10]. They found that the addition of SBE obtained interconnected and irregularshaped pores. On $40 \mathrm{wt}$. \% SBE, the micrograph shows the formation of bigger pores from $4.2 \mu \mathrm{m}$ to $7 \mu \mathrm{m}$ when the heating rate increased. This indicated that a microstructure failure from the entrapment of gasses was obtained on the samples. The above finding is consistent with the previous study by Cicek et al. [5]. Cicek et al. [5] found that the irregular and big pore shapes at high glass content and high heating rate were due to the entrapment of gasses. At $4{ }^{\circ} \mathrm{C} / \mathrm{min}$, small pores and dense surface were seen as compared to $2^{\circ} \mathrm{C} / \mathrm{min}$. However, the scattered quantity of holes is shown in Figure 9 when observed at high magnification of $20 \mathrm{~K}$ on dense surface area. The holes were believed to be the result of a higher porosity of $4{ }^{\circ} \mathrm{C} / \mathrm{min}$ as compared to $2{ }^{\circ} \mathrm{C} / \mathrm{min}$ and contributed to a lower density. On $45 \mathrm{wt} \% \mathrm{SBE}$, less quantity of pores was observed when the heating rate increased. This microstructure supported the lower porosity result when the heating rate increased. However, the microstructure of the produced sample showed rough phases of grains, not densified and not uniform for all heating rates. The observations on this microstructure revealed the lower densities of GCC on 45 wt. \% SBE. This showed that the $2{ }^{\circ} \mathrm{C} / \mathrm{min}$ interval was not high enough to have a good dispersion of nuclei. The virtuous nuclei dispersion is important for sequence crystal growth with more uniform and densified microstructure.

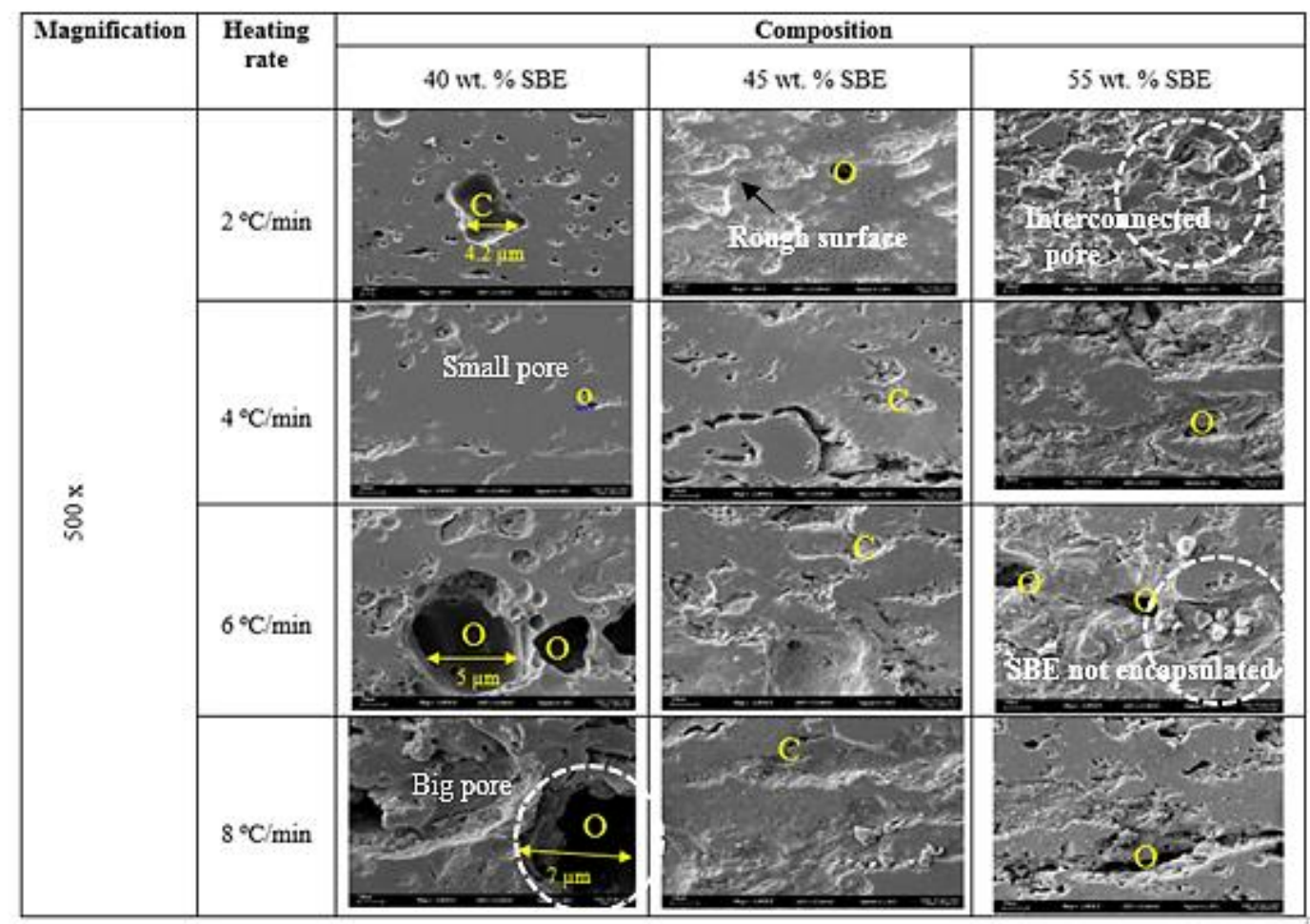

Figure 8. SEM micrographs at different batch formulations and heating rates ( $\mathrm{C}$ denotes closed pore and $\mathrm{O}$ is open pore). 
For $55 \mathrm{wt} . \% \mathrm{SBE}$, at $2{ }^{\circ} \mathrm{C} / \mathrm{min}$, the surface was less uniform, less even and less densified as compared to the higher heating rates of $4,6,8^{\circ} \mathrm{C} / \mathrm{min}$, respectively, thus proving that the heating rate should be higher At a slow heating rate, more interconnected pores were present as compared to a fast heating rate. Similar results related to low glass addition were obtained by Cicek et al. [5]. In addition, the rough grain area was observed on all heating rates. The micrograph of sample $55 \mathrm{wt} . \%$ SBE on the dotted circle revealed that the SBE particles were not fully encapsulated and it can be seen that they were chipped out from GCC. This situation contributed to the less changes of physical properties for all the heating rates. Moreover, increasing the heating rate did not contribute to the promising properties. It is shown that the $2{ }^{\circ} \mathrm{C} / \mathrm{min}$ interval was not high enough to have a good dispersion of nuclei. It is suggested that at high SBE content, in order to have a uniform and densified microstructure with less pores, a higher interval than $2{ }^{\circ} \mathrm{C} / \mathrm{min}$ is required to be sintered on the GCC. A good surface condition amongst these samples was observed at $40 \mathrm{wt} . \% \mathrm{SBE}$ at $2{ }^{\circ} \mathrm{C} / \mathrm{min}$ where the surface of the sample was absent with big pores. It can be seen that the recycled SLS glass was able to retain most of the spent bleach earth particle that resulted in a densified GCC. However, the sample was still exposed to the pore formation. It can be seen that increase in heating rate and SBE loading had an influence on the microstructure of green GCC studied in this work. Therefore, the heating rate of $2{ }^{\circ} \mathrm{C} / \mathrm{min}$ will be used as a fixed heating rate for further investigation.

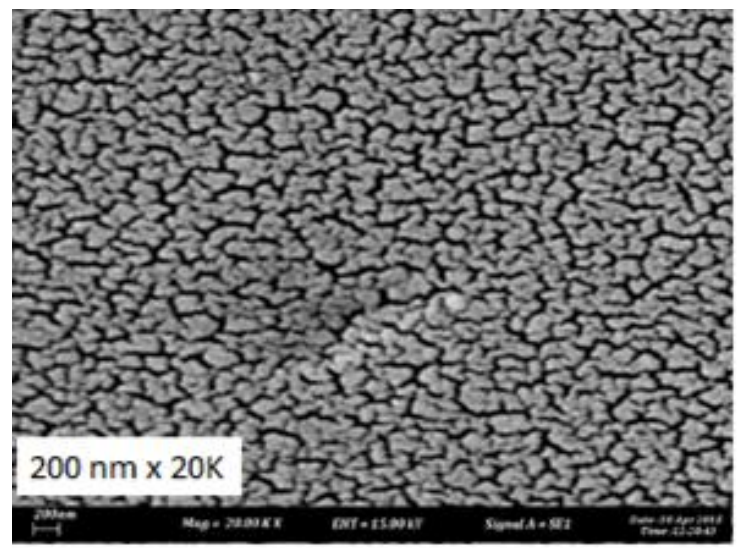

Figure 9. SEM micrograph of scattered holes of sample $40 \mathrm{wt} \%$ at $4{ }^{\circ} \mathrm{C} / \mathrm{min}$

\section{CONCLUSIONS}

The effects of heating rates on the sintered properties of SBE composite were investigated. The SBE composites were subjected to a series of thermal treatments in order to optimise the heating rate. The heating rate increase slightly enhanced the microstructure, thereby changing of the properties such as density, water absorption and porosity was successfully derived in the SBE/recycled glass composite prepared at different loadings of SBE and subsequent heating rates regime. The physical properties correlated to the precipitation phases present in the composite. SEM analysis showed that there were slight variations in the morphology of the phases and microstructure with the changes in the heating rate. These findings encourage further investigation in establishing standardised parameters for the heat treatment of SBE/recycled glass composite that could serve as the basis for processing and handling protocols during formation. 


\section{ACKNOWLEDGEMENTS}

We are grateful for the financial support by Centre for Research and Innovation Management, Universiti Teknikal Malaysia, Melaka through PJP/2013/FKP (9A)/S01190. Special thanks also to UMP and Jabatan Mineral Ipoh for the supply of spent bleach earth and soda lime silicate glass.

\section{REFERENCES}

[1] Sanad MMS, Rashad MM, Abdel-Aal EA, El-Shahat MF. Mechanical, morphological and dielectric properties of sintered mullite ceramics at two different heating rates prepared from alkaline monophasic salts. Ceramics International. 2013;39:1547-54.

[2] Marshall RE, Farahbakhsh K. Systems approaches to integrated solid waste management in developing countries. Waste Manag. 2013;33:988-1003.

[3] Ponsot I, Bernardo E. Self glazed glass ceramic foams from metallurgical slag and recycled glass. Journal of Cleaner Production. 2013;59:245-50.

[4] Lemazurier L, Shidore N, Kim N, Moawad A, Rousseau A, Bonkoski P, et al. Impact of advanced engine and powertrain technologies on engine operation and fuel consumption for future vehicles. SAE Technical Paper; 2015.

[5] Cicek B, Tucci A, Bernardo E, Will J, Boccaccini AR. Development of glassceramics from boron containing waste and meat bone ash combinations with addition of waste glass. Ceramics International. 2014;40:6045-51.

[6] Juoi JM, Arudra D, Rosli ZM, Hussain K, Japper Jaafar A. Microstructural properties of glass composite material made from incinerated scheduled waste slag and soda lime silicate (SLS) waste glass. Journal of Non-Crystalline Solids. 2013;367:8-13.

[7] Beshara A, Cheeseman CR. Reuse of spent bleaching earth by polymerisation of residual organics. Waste Manag. 2014;34:1770-4.

[8] Loh SK, James S, Ngatiman M, Cheong KY, Choo YM, Lim WS. Enhancement of palm oil refinery waste - Spent bleaching earth (SBE) into bio organic fertilizer and their effects on crop biomass growth. Industrial Crops and Products. 2013;49:775-81.

[9] Boey P-L, Saleh MI, Sapawe N, Ganesan S, Maniam GP, Ali DMH. Pyrolysis of residual palm oil in spent bleaching clay by modified tubular furnace and analysis of the products by GC-MS. Journal of Analytical and Applied Pyrolysis. 2011;91:199-204.

[10] Eliche-Quesada D, Corpas-Iglesias FA. Utilisation of spent filtration earth or spent bleaching earth from the oil refinery industry in clay products. Ceramics International. 2014;40:16677-87.

[11] Teixeira SR, Magalhaes RS, Arenales A, Souza AE, Romero M, Rincon JM. Valorization of sugarcane bagasse ash: producing glass-ceramic materials. Journal of Environmental Management. 2014;134:15-9.

[12] Bernardo E, Castellan R, Hreglich S. Sintered glass-ceramics from mixtures of wastes. Ceramics International. 2007;33:27-33.

[13] Banerjee S, Mahapatro D, Dubey S. Some study on electrical discharge machining of ( $\{\mathrm{WC}+\mathrm{TiC}+\mathrm{TaC} / \mathrm{NbC}\}-\mathrm{Co})$ cemented carbide. The International Journal of Advanced Manufacturing Technology. 2008;43:1177-88. 
[14] Pontikes Y, Esposito L, Tucci A, Angelopoulos GN. Thermal behaviour of clays for traditional ceramics with soda-lime-silica waste glass admixture. Journal of the European Ceramic Society. 2007;27:1657-63.

[15] Alizadeh P, Yousefi M, Yekta BE, Ghafoorian N, Molaie F. Sintering behavior of $\mathrm{SiO}_{2}-\mathrm{CaO}-\mathrm{MgO} \quad\left(\mathrm{Na}_{2} \mathrm{O}\right)$ glass-ceramics system. Ceramics International. 2007;33:767-71.

[16] Tulyaganov DU, Agathopoulos S, Ventura JM, Karakassides MA, Fabrichnaya $\mathrm{O}$, Ferreira JMF. Synthesis of glass-ceramics in the $\mathrm{CaO}-\mathrm{MgO}-\mathrm{SiO}_{2}$ system with $\mathrm{B}_{2} \mathrm{O}_{3}, \mathrm{P}_{2} \mathrm{O}_{5}, \mathrm{Na}_{2} \mathrm{O}$ and $\mathrm{CaF}_{2}$ additives. Journal of the European Ceramic Society. 2006;26:1463-71.

[17] Junkes JA, Prates PB, Hotza D, Segadães AM. Combining mineral and clay-based wastes to produce porcelain-like ceramics: An exploratory study. Applied Clay Science. 2012;69:50-7.

[18] Wan W, Feng Y, Yang J, Xu S, Qiu T. Preparation of mesoporous silica ceramics with relatively high strength from industrial wastes by low-toxic aqueous gelcasting. Journal of the European Ceramic Society. 2015;35:2163-70.

[19] Mana M, Ouali MS, de Menorval LC. Removal of basic dyes from aqueous solutions with a treated spent bleaching earth. Journal of Colloid and Interface Science. 2007;307:9-16.

[20] Erol M, Kucukbayrak S, Ersoy-Mericboyu A. Comparison of the properties of glass, glass-ceramic and ceramic materials produced from coal fly ash. Journal of Hazardous Materials. 2008;153:418-25.

[21] Erol M, Küçükbayrak S, Ersoy-Meriçboyu A. Production of glass-ceramics obtained from industrial wastes by means of controlled nucleation and crystallization. Chemical Engineering Journal. 2007;132:335-43.

[22] Ponsot I, Falcone R, Bernardo E. Stabilization of fluorine-containing industrial waste by production of sintered glass-ceramics. Ceramics International. 2013;39:6907-15.

[23] Salman SM, Salama SN, Abo-Mosallam HA. The crystallization behaviour and bioactivity of wollastonite glass-ceramic based on $\mathrm{Na}_{2} \mathrm{O}-\mathrm{K}_{2} \mathrm{O}-\mathrm{CaO}-\mathrm{SiO}_{2}-\mathrm{F}$ glass system. Journal of Asian Ceramic Societies. 2015;3:255-61. 